\section{Effective endoscopic holmium laser lithotripsy in the treatment of a large impacted gallstone in the duodenum}

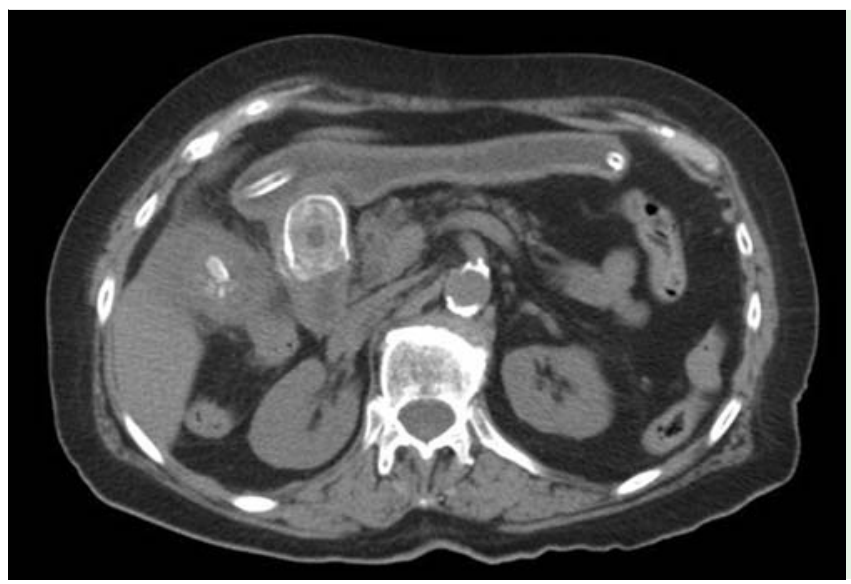

Gallstone ileus is caused by the passage of one or more large gallstones (at least $2.5 \mathrm{~cm}$ in size) in the gastrointestinal tract through a bilioenteric fistula. It accounts for $1 \%$ to $4 \%$ of all cases of mechanical small-bowel obstruction [1,2]. The obstructing gallstone is usually impacted in the terminal ileum, rarely the duodenum [1]. Computed tomography generally reveals mechanical bowel obstruction, pneumobilia, and an ectopic stone in the intestinal lumen (Rigler's triad) [3]. Although surgery is considered the gold standard treatment, a less invasive endoscopic approach is advisable in high risk patients [4].

An 87-year-old woman was admitted to the emergency department with abdominal pain and vomiting of 3 days' duration. Computed tomography showed a large, calcified ring in the duodenum and aerobilia ( Fig.1). Upper gastrointestinal endoscopy revealed a large obstructive stone in the duodenal bulb that could not be removed endoscopically, even after pyloric dilation. Because of the obstructive symptoms, a gastrojejunal anastomosis was created, which partially relieved the obstruction.
Endoscopic holmium laser lithotripsy treatment of a large impacted gallstone in the duodenum.
Fig. 1 Computed tomographic scan shows a large calcified ring (stone) in the duodenum of an 87-year-old woman presenting with abdominal pain and vomiting of 3 days' duration.

The patient was discharged after 15 days with complete resolution of the occlusive symptoms, and her scheduled cholecystectomy was canceled.

Endoscopy_UCTN_Code_CCL_1AZ_2AD

Competing interests: None

\section{Vincenzo Mirante, Helga Bertani, Giuseppe Grande, Mauro Manno, Angelo Caruso, Santi Mangiafico, Rita Conigliaro}

U.O.C. Gastroenterology and Digestive Endoscopy Unit, Nuovo Ospedale Civile Sant'Agostino Estense, Modena, Italy

\section{References}

1 Reisner RM, Cohen JR. Gallstone ileus: a review of 1001 reported cases. Am Surg 1994; 60: 441 - 446

2 Rodriguez H, Codina C, Girones V et al. Gallstone ileus: results of analysis of a series of 40 patients. Gastroenterol Hepatol 2001; 24: $489-494$

3 Rigler LG, Borman CN, Noble JF. Gallstone obstruction: pathogenesis and roentgen manifestations. JAMA 1941; 117: 1753-1759

4 Goldstein EB, Savel RH, Pachter HL et al. Successful treatment of Bouveret syndrome using holmium: YAG laser lithotripsy. Am Surg 2005; 71: $882-885$ in fragmentation of the stone into smal parts, which were removed with an extraction basket and a retrieval device (৫ Video 1).

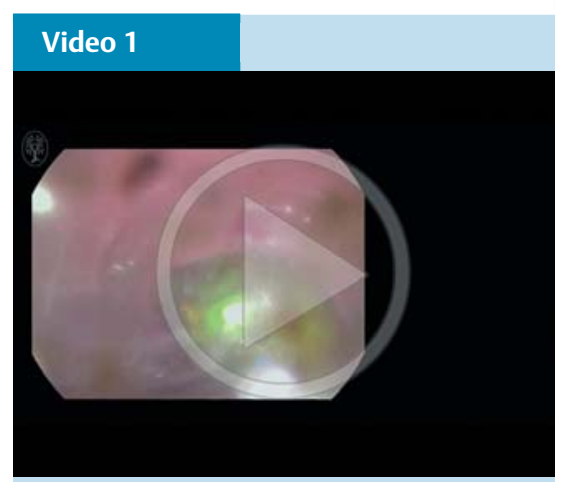

Bibliography

Dol http://dx.doi.org/

10.1055/s-0034-1393150

Endoscopy 2015; 47: E485

(c) Georg Thieme Verlag KG

Stuttgart · New York

ISSN 0013-726X

Corresponding author

\section{Vincenzo Mirante, MD}

Gastroenterology and Digestive Endoscopy Unit Nuovo Ospedale Civile Sant'Agostino Estense Via Pietro Giardini 1355

41126 Modena

Italy

Fax: +39-59-3961216

v.mirante@libero.it 